\title{
Impacts of food contact chemicals on human health: a consensus statement
}

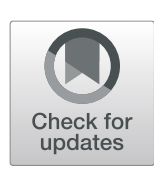

Jane Muncke ${ }^{1^{*}}$ D, Anna-Maria Andersson², Thomas Backhaus ${ }^{3}$, Justin M. Boucher ${ }^{4}$, Bethanie Carney Almroth ${ }^{3}$, Arturo Castillo Castillo ${ }^{5}$, Jonathan Chevrier ${ }^{6}$, Barbara A. Demeneix ${ }^{7}$, Jorge A. Emmanuel ${ }^{8}$, Jean-Baptiste Fini', David Gee ${ }^{9}$, Birgit Geueke ${ }^{1}$, Ksenia Groh ${ }^{1}$, Jerrold J. Heindel ${ }^{10}$, Jane Houlihan ${ }^{11}$, Christopher D. Kassotis ${ }^{12}$, Carol F. Kwiatkowski ${ }^{13}$, Lisa Y. Lefferts ${ }^{14}$, Maricel V. Maffini ${ }^{15}$, Olwenn V. Martin ${ }^{16}$, John Peterson Myers ${ }^{17,18}$, Angel Nadal ${ }^{19}$, Cristina Nerin ${ }^{20}$, Katherine E. Pelch ${ }^{13}$, Seth Rojello Fernández ${ }^{21}$, Robert M. Sargis ${ }^{22}$, Ana M. Soto ${ }^{23}$, Leonardo Trasande ${ }^{24}$, Laura N. Vandenberg ${ }^{25}$, Martin Wagner ${ }^{26}$, Changqing Wu ${ }^{27}$, R. Thomas Zoeller ${ }^{28}$ and Martin Scheringer ${ }^{4,29}$

\begin{abstract}
Food packaging is of high societal value because it conserves and protects food, makes food transportable and conveys information to consumers. It is also relevant for marketing, which is of economic significance. Other types of food contact articles, such as storage containers, processing equipment and filling lines, are also important for food production and food supply. Food contact articles are made up of one or multiple different food contact materials and consist of food contact chemicals. However, food contact chemicals transfer from all types of food contact materials and articles into food and, consequently, are taken up by humans. Here we highlight topics of concern based on scientific findings showing that food contact materials and articles are a relevant exposure pathway for known hazardous substances as well as for a plethora of toxicologically uncharacterized chemicals, both intentionally and non-intentionally added. We describe areas of certainty, like the fact that chemicals migrate from food contact articles into food, and uncertainty, for example unidentified chemicals migrating into food. Current safety assessment of food contact chemicals is ineffective at protecting human health. In addition, society is striving for waste reduction with a focus on food packaging. As a result, solutions are being developed toward reuse, recycling or alternative (non-plastic) materials. However, the critical aspect of chemical safety is often ignored. Developing solutions for improving the safety of food contact chemicals and for tackling the circular economy must include current scientific knowledge. This cannot be done in isolation but must include all relevant experts and stakeholders. Therefore, we provide an overview of areas of concern and related activities that will improve the safety of food contact articles and support a circular economy. Our aim is to initiate a broader discussion involving scientists with relevant expertise but not currently working on food contact materials, and decision makers and influencers addressing single-use food packaging due to environmental concerns. Ultimately, we aim to support science-based decision making in the interest of improving public health. Notably, reducing exposure to hazardous food contact chemicals contributes to the prevention of associated chronic diseases in the human population.
\end{abstract}

Keywords: Food contact material, Migration, Food packaging, Non-intentionally added substance, Chronic disease, Human health, Mixture toxicity, Endocrine disrupting chemical, Sustainable packaging, Circular economy

\footnotetext{
* Correspondence: jane.muncke@fp-forum.org

${ }^{1}$ Food Packaging Forum Foundation, Zurich, Switzerland

Full list of author information is available at the end of the article
}

(c) The Author(s). 2020 Open Access This article is distributed under the terms of the Creative Commons Attribution 4.0 International License (http://creativecommons.org/licenses/by/4.0/), which permits unrestricted use, distribution, and reproduction in any medium, provided you give appropriate credit to the original author(s) and the source, provide a link to the Creative Commons license, and indicate if changes were made. The Creative Commons Public Domain Dedication waiver (http://creativecommons.org/publicdomain/zero/1.0/) applies to the data made available in this article, unless otherwise stated. 


\section{Background}

We, as scientists working on developmental biology, endocrinology, epidemiology, toxicology, and environmental and public health, are concerned that public health is currently insufficiently protected from harmful exposures to food contact chemicals (FCCs). Importantly, exposures to harmful FCCs are avoidable. Therefore, we consider it our responsibility to bring this issue to the attention of fellow scientists with relevant expertise, but currently not engaged in the area of FCMs, as well as decision makers and influencers in government, industry and civil society dealing with environmental and health-related aspects of food packaging. We propose that a broader, multi-stakeholder dialogue is initiated on this topic and that the issue of chemical safety of food packaging becomes a central aspect in the discussions on sustainable packaging.

Food contact chemicals (FCCs) are the chemical constituents of food contact materials and finished food contact articles, including food packaging, food storage containers, food processing equipment, and kitchen- and tableware $[1,2]$. We define FCCs as all the chemical species present in food contact articles, regardless of whether they are intentionally added or present for other reasons.

It is clearly established by empirical data that FCCs can migrate from food contact materials and articles into food, indicating a high probability that a large majority of the human population is exposed to some or many of these chemicals [3]. Indeed, for some FCCs there is evidence for human exposure from biomonitoring [4-11], although some FCCs may have multiple uses and also non-food contact exposure pathways.

When food contact material regulations were first developed, it had been generally assumed that low-level chemical exposures, i.e. exposures below the toxicologically established no-effect level, pose negligible risks to consumers, except for carcinogens [12, 13]. However, more recent scientific information demonstrates that this assumption is not generally valid, with the available evidence showing that exposure to low levels of endocrine disrupting chemicals can contribute to adverse health effects [14-20]. In addition, chemical mixtures can play a role in the development of adverse effects [21-24], and human exposure to chemical mixtures is the norm but currently not considered when assessing health impacts of FCCs [1]. The timing of exposures during fetal and child development is another critical aspect for understanding development of chronic disease [25]. Currently, these new and important insights are still insufficiently considered in the risk assessment of chemicals in general, and of FCCs in particular [20]. We have previously published an in-depth analysis of the scientific shortcomings of the current chemical risk assessment for food contact materials in Europe and the US
[1]. For example, in the European Union (EU) the regulation EU 10/2011 includes a list of authorized substances for the manufacture of plastic materials and articles in contact with food and, for some of the chemicals, their permitted maximum concentration, either in the plastic food contact article or in food (i.e. specific migration limit) [26]. However, there are still many substances that are present in plastics and other materials as non-intentionally added substances (NIAS). Even though the EU regulations 10/2011 explicitly and EU $1935 / 2004$ generally require a risk assessment of NIAS, there are many difficulties: first, identification of NIAS is very demanding [27] and, secondly, studying the effects on human health is often not possible because for example the chemicals are not available as pure substances or testing would be too expensive [1]. What is more, there is no regulatory requirement to assess toxic effects of the chemical mixtures migrating from food contact articles [1]. To summarize, we are concerned that current chemical risk assessment for food contact chemicals does not sufficiently protect public health.

Therefore, we would like to bring the following statement to the attention of policy makers and stakeholders, especially those currently working on the issue of packaging waste but not focusing on the chemical safety of food contact articles (Table 1). By mapping the challenges (Table 2), we aim to initiate a broader debate that also involves scientists with different expertise of relevance to the issue. Importantly, chemical safety must be addressed in two ways: e.g. (i) a discussion of how chemical safety is ensured, based on the current scientific understanding and e.g. (ii) a debate of the chemical safety of food packaging in the circular economy, which aims at minimizing waste, energy and resources use [28]. Therefore, we provide an overview of the most pressing challenges based on current scientific understanding. Ultimately, the public is to be protected from exposures to hazardous FCCs while at the same time the aims of the circular economy need to be achieved. To reach these goals, we think that there is a need to better inform decision making on future food packaging research and policy.

\section{Part 1. Facts based on established scientific data and findings}

Chemicals migrate from all types of food contact materials and articles

Chemicals can transfer from food contact materials and articles into food. This phenomenon is known as migration and has been studied since the 1950s [29-33]. All types of food contact materials may exhibit chemical migration, but the types of migrating chemicals and their levels differ significantly. There are around 1200 peerreviewed scientific studies clearly demonstrating migration of multiple FCCs from food contact materials and 
Table 1 Overview of relevant stakeholders from the food contact and circular economy domains. Inter-governmental organizations could convene these stakeholders from different backgrounds and initiate topical discussions on the issues detailed in Table 2

\begin{tabular}{ll}
\hline Stakeholder group & Description \\
\hline Intergovernmental organization & Staff and expert working groups of the World Health Organization, Food and Agriculture Organization, \\
United Nations Environment Programme, etc. & Global government officials and regulatory authority experts in the areas of food contact and \\
Regulatory & Eircular economy \\
Enforcement & Experts in government agencies, third-party labs, industry and international working groups \\
Risk assessment & Experts designing and developing new "sustainable packaging" or business models for food \\
Packaging and product design & products in circular economies \\
Global food production & Multinational food (processing) industry experts and decision makers \\
Local food production & Farmers and primary producers, hospitality sector representatives \\
Retail & Decision makers and experts on distribution of locally and globally produced foods \\
Food packaging manufacturing & Chemical manufacturers (polymers, additives), converters, packaging manufacturers and their \\
Food contact article manufacturing & supply chains \\
& Chemical manufacturers, food processing equipment manufacturers, kitchen- and tableware \\
Waste management & Government officials, industry experts and providers \\
Civil society & Environmental and health NGOs, consumer advocacy groups, food movements \\
Science & Academics, researchers in industry, governments, and NGOs, independent scientific consultants
\end{tabular}

articles (for example [29-32, 34-66]). Migration is affected by temperature, storage time, the chemistry of both the food contact article and food, the thickness of the food contact layer, and the packaging size (proportionally higher migration from smaller packaging sizes due to the increasing surface-area-to-volume ratio).

\section{Several thousands of chemicals are intentionally used to make food contact articles}

Analysis of FCC lists issued by legislatures, industry, and NGOs worldwide indicates that almost 12,000 distinct chemicals may be used in the manufacture of food contact materials and articles [67]. For example, European Union (EU) and EU Member State regulations list a total of 8030 substances for use in different types of food contact articles [68]. In the United States (US), 10,787 substances are allowed as direct or indirect food additives, and roughly half of these are FCCs [69]. Many additional FCCs may be used in the US under the assumption of being generally recognized as safe (GRAS), but they are not notified to the US Food and Drug Administration (FDA) and therefore no public record on their use is available [70]. In general, information on the actual use of a chemical in food contact materials (and its levels) is difficult to obtain $[71,72]$.

Toxicity and exposure information is available only for few of the intentionally used chemicals

All migrating FCCs have inherent toxicity properties that can cause different effects at different doses and are related to the timing of exposure, mode of action, and other aspects. At the same time, levels of FCCs that humans are exposed to reflect their use (or presence) in a food contact article and are associated with its concentration in food. To evaluate the risk of a given chemical to human health, information on its inherent toxicity (i.e., its hazard) and the actual levels of exposure is needed.

Many of the chemicals that are intentionally used in the manufacture of food contact articles have not been tested for hazard properties at all, or the available toxicity data are limited [67]. Moreover, endocrine disruption, as a specific hazard of concern, is not routinely assessed for chemicals migrating from food contact articles, although some chemical migrants are known endocrine disruptors [73-77].

Exposure data are commonly based on assumptions or estimates - for example derived from dietary assessments or unpublished (proprietary) data of an intentionally used FCC's concentration in a food contact article [71, 78, 79]. Thus, there is significant uncertainty associated with these data. In short, decisions on the use of a chemical in food contact materials are commonly made in data-poor situations.

\section{Known hazardous chemicals are authorized for use in food contact}

Substances of very high concern (SVHC) are defined under the EU regulation on the Registration, Evaluation, Authorisation and Restriction of Chemicals (REACH) as chemicals with unacceptable hazard properties (like carcinogenicity, mutagenicity, toxicity for reproduction, persistence and bioaccumulation, or endocrine disruption). The human health effects of chemicals used in the manufacture of food contact materials are not covered by 
Table 2 Topics of concern (based on Table 2 [1]) and examples of activities addressing them. This is not a complete and comprehensive overview but rather a starting point for further discussions that essentially need to involve many stakeholders (see Table 1)

\begin{tabular}{llll}
\hline Area & Topic & Description & Example \\
\hline A. DATA GAPS & $\begin{array}{l}\text { 1. Information on chemicals used in food contact } \\
\text { materials }\end{array}$ & $\begin{array}{l}\text { Characterize types of chemicals used in } \\
\text { the manufacture of FCMs and FCAs, their } \\
\text { functions and levels }\end{array}$ \\
& $\begin{array}{l}\text { 2. Information on non-intentionally added } \\
\text { substances }\end{array}$ & $\begin{array}{l}\text { Compile existing information, develop strategies } \\
\text { and work plans to fill data gaps }\end{array}$ \\
& $\begin{array}{l}\text { 3. Information on migration of food contact } \\
\text { chemicals }\end{array}$ & $\begin{array}{l}\text { Provide systematic overview of evidence for } \\
\text { migration from FCMs and FCAs }\end{array}$
\end{tabular}

4. Empirical exposure data

B. METHODOLOGY GAPS AND NEEDS

C. UPDATE REGULATORY PROCESSES
5. Comprehensive definition of adverse effects

6. Approaches to addressing non-monotonic dose response

7. Approaches to addressing mixture toxicity

8. Develop a framework to address aggregate exposures

9. Develop a framework to address cumulative exposures

10. Modernize tiered approach for screening and prioritization

11. Compile information on human health outcomes of exposure to FCCs

12. Overall regulatory framework for evaluation beyond sector-specific regulations

13. Requirements for data on use of FCCs

14. Need to reassess substances authorized for use and/or generally recognized as safe

15. Address bias in risk assessment

16. Ensure transparency of decisions

17. Improve enforcement

18. Multi-stakeholder dialogues on practical solutions

19. Integrate food packaging waste and safety considerations
Measure migration into actual foods, assess intake for different demographics (age groups, ethnic and regional diversity)

Expand the scope of toxicological testing requirements to include non-cancer related endpoints such as effects on the nervous, immune and endocrine systems, and cardiovascular and metabolic effects

Develop practical tools for use in chemical risk assessment of FCCs

Develop overall migrate testing for finished FCAs that can be used in the regulatory context, including standardized sample preparation

Integrate exposure information from different legislative areas when setting safe exposure thresholds

Assess the safety of exposures to different chemicals through the same or different exposure routes

Include additional relevant endpoints for toxicity testing, include testing of finished FCA

Assess systematically the available evidence for how FCCs adversely impact human health; highlight data gaps showing the need for appropriate longitudinal studies that assess food contact chemicals

Combine chemical hazard and possibly risk assessment for different sectors in one legal framework

Based on the principles of REACH, set legal requirement to provide information about chemical use for market access

Policy instruments for removing authorized chemicals e.g. indirect food additives, EU starting substances and additives for plastic FCMs

Ensure that scientific judgement is placed in context of personal values, acknowledge other sources of bias and balance expert groups accordingly

Communicate potential or real bias of decision makers and experts making recommendations for decision makers

Raise awareness to provide resources for enforcement authorities to expand activities

Address two key topics: 1.) Definition of safety for FCCs: update according to current scientific knowledge: 2.)Food packaging in the circular economy: chemical safety considerations

Policy must address both aspects simultaneously to avoid conflicting goals 
Table 2 Topics of concern (based on Table 2 [1]) and examples of activities addressing them. This is not a complete and comprehensive overview but rather a starting point for further discussions that essentially need to involve many stakeholders (see Table 1) (Continued)

\begin{tabular}{|c|c|c|c|}
\hline Area & Topic & Description & Example \\
\hline \multirow[t]{4}{*}{$\begin{array}{l}\text { D. REPLACING } \\
\text { HAZARDOUS FCCS }\end{array}$} & 20. Developing safer alternatives & $\begin{array}{l}\text { Based on revised definition of safety and updated toxicity } \\
\text { testing; develop screening assays for endocrine disruption } \\
\text { and other relevant endpoints }\end{array}$ & $\begin{array}{l}{[134,} \\
143]\end{array}$ \\
\hline & 21. Testing finished food contact articles & $\begin{array}{l}\text { Use combination of toxicity testing and chemical analysis } \\
\text { ("Effect-directed analysis") to screen for hazardous but } \\
\text { unknown FCCs }\end{array}$ & [95] \\
\hline & $\begin{array}{l}\text { 22. Integrating human health with environmental } \\
\text { considerations: life cycle approach }\end{array}$ & $\begin{array}{l}\text { Develop integrative assessment for environmental and } \\
\text { human health impacts, e.g. using life cycle analysis or } \\
\text { other method }\end{array}$ & [144] \\
\hline & 23. Update sustainable packaging concept & $\begin{array}{l}\text { Define sustainable packaging to also include aspects } \\
\text { of human health protection that are based on current } \\
\text { scientific understanding }\end{array}$ & \\
\hline
\end{tabular}

REACH. However, the toxicity properties of SVHCs are identical regardless of their use. Several SVHCs (i.e., known hazardous chemicals) are authorized for use in food contact in Europe and other countries [80]. For several SVHCs, as well as other known hazardous substances, there is evidence for migration from food contact articles [73], for example migration of several ortho-phthalates [81], per- and polyfluoroalkyl substances [63, 82-84], and perchlorate [85]. Notably, for substances classified as SVHCs there is a societal consensus in Europe that their use shall be phased out. Furthermore, in a circular economy, where food packaging is made from recycled materials, it is essential to ensure that no hazardous chemicals are present in the materials because it will be very difficult, if not impossible, to manage their risks effectively.

\section{Food contact articles contain non-intentionally added substances (NIAS) and most are unknown}

In addition to intentionally used chemicals, food contact articles also contain non-intentionally added substances (NIAS) that may or may not have a technical function. NIAS are impurities of starting substances or additives, reaction by-products generated during manufacture along the entire supply chain, or break-down products, e.g. from additives [86]. More and more NIAS, including those with evidence for migration, have been detected by modern analytical methods, but many remain unidentified due to prevailing limitations in structure elucidation $[27,55,74$, 87-95]. However, it is well known that for several types of food contact materials, migration of NIAS is more significant than migration of intentionally used substances $[3,96]$. In conclusion, there are many unknown and/or untested chemicals present in food contact articles.

Risk assessment of unknown chemicals is not possible under the current regulatory approach

All migrating FCCs need to be assessed for their risk to human health, and this requires information on both hazard and exposure levels. But these data cannot be generated for chemicals with unknown identity. Therefore, the conventional risk assessment approach cannot be applied to assessing the safety of these unidentified FCCs [1]. Moreover, these NIAS contribute to the mixture of migrating chemicals, which likewise cannot be evaluated by conventional risk assessment strategies. This implies that the human population is exposed to unknown and/or untested chemicals migrating from food contact articles, with unknown health implications.

\section{Humans are exposed daily to mixtures of chemicals migrating from food contact articles into food}

A chemical mixture can cause adverse effects even if all individual components of the mixture are present at individually safe levels. Mixture toxicity is a scientifically well-described phenomenon [23]. In general, FCCs migrating from food contact articles are assessed for their safety on a substance-by-substance basis. However, chemical migration occurs in mixtures, therefore humans are also exposed to chemical mixtures [1]. In addition to chemicals migrating from food contact articles, humans are exposed to chemicals from other sources, such as personal care products, food contaminants or textiles.

\section{Part 2. Areas of uncertainty}

FCCs from food contact articles are a significant source of chemical exposure

In the US, 40,655 chemicals are used in commerce today [97] and in Europe 22,169 substances have been registered under REACH [98]. Human exposure has been systematically assessed for a fraction of these chemicals, including for some FCCs $[4,99-105]$. However, for the majority of FCCs it remains unknown if humans are exposed and at what levels. At least 3221 exogenous chemicals have been measured in human blood [106]. Various xenobiotics have frequently been found in pregnant women, in the placenta and cord blood, indicating that fetal exposure to mixtures 
of xenobiotics is the norm [107-111], and the health impacts of this mixture exposure during early life remain largely unknown, but effects on the human brain (i.e. decreased intelligence in children that were exposed prenatally to a mixture of EDCs) have been shown [21]).

Approximately 12,000 intentionally added substances [67] and 30,000 to 100,000 non-intentionally added substances potentially migrate into food from various food contact articles [112]. Appropriate chemical-analytical methods are lacking for most of them [27, 90, 95, 113, 114], which makes it currently impossible to discern the contribution of these chemicals to the overall human exposure to xenobiotics. However, food packaging is estimated to be the most relevant source of human exposure to plasticizers [71, 115]. For comparison: it is well known that the concentrations of FCCs in foodstuffs exceed the concentrations of e.g. pesticide residues in food by at least a factor of 100 [3]. Moreover, there are fewer than 1000 pesticides in commercial use, and chemical-analytical methods are available for all of them, including their main metabolites.

\section{Using generic thresholds for the safety assessment of FCCs is inadequate}

For FCCs without hazard data, generic concentration thresholds are commonly used in their risk assessment. For example, in Europe unauthorized chemicals may be used in food contact plastics if their migration into food is below the detection limit of $10 \mathrm{ppb}(10 \mu \mathrm{g} / \mathrm{kg}$ food), and if they are not genotoxic, mutagenic, toxic to reproduction, or substances in nano-form [26]. In practice this detection limit is often interpreted as a safety threshold, for example in the revised Japanese FCM legislation [116]. In the US, $0.5 \mathrm{ppb}(0.5 \mu \mathrm{g} / \mathrm{kg}$ food) is the Threshold of Regulation: for FCCs migrating below this threshold, no hazard data need to be provided if the chemical's structure has no alerts for genotoxicity [117]. But this approach is inadequate because it assumes that "the dose makes the poison". According to the current scientific understanding of non-monotonic dose responses, this is clearly not always the case $[18,19]$. Deriving a safe threshold may not be straightforward for chemicals with non-monotonic dose responses, such as for endocrine disrupting chemicals [14], because the results of standard high-dose toxicity testing cannot simply be extrapolated to the low-dose range. Chemicals with non-monotonic dose responses not only have increasing effects with increasing dose but may also have effects in the low-dose range $[15,19]$. A study commissioned by the European Food Safety Authority concluded that non-monotonic dose responses for several food-related chemicals (such as FCCs) could neither be confirmed nor rejected, and further investigation has been recommended [118]. Guidance for addressing this difficulty in chemical risk assessment has been published [119]. Therefore, we find it concerning that this aspect is not being taken up in general by (regulatory) chemical risk assessment as it implies that humans are unnecessarily exposed to hazardous chemicals.

\section{Humans may be exposed to FCCs also from sources that are non-food contact articles}

Exposure levels to a given FCC need to be known to determine if there is a risk, as a chemical's risk is related to both exposure and hazard. But in practice, obtaining exposure data for FCCs is difficult, as the European research project FACET has demonstrated [78], because there is no systematic surveillance. As a result, exposure levels of FCCs are mostly based on estimates, which are associated with uncertainty and potentially underestimate actual risk [79].

In addition, humans can be exposed to an FCC from non-food contact sources (e.g. bisphenol A from food packaging and thermal-paper receipts), too. This implies that aggregate exposure is probable for at least some FCCs $[101,120]$. Therefore, a threshold approach based on exposure from only a single source may lead to an underestimation of actual human risk since the actual exposure is underestimated.

\section{Combined exposure to mixtures of FCCs increases risk to human health}

Combination effects are not adequately addressed, even though it is known that chemicals migrate from food contact articles in mixtures. Novel approaches, such as effect-directed analysis, where in vitro toxicity testing is combined with chemical analysis, or semiquantitative assessments, where chemicals with assumed highest exposure levels are identified, can be useful for prioritization of analytical chemistry work to identify chemicals of concern in mixtures [27, 74-76, 86, 92, 121]. In vitro screening for some aspects of endocrine disruption can be used to assess such hazard properties in the overall migrate, but the sample preparation, assay selection and data interpretation aspects need to be further developed $[75,95,122-124]$.

\section{The consequences of human exposure to FCCs need careful investigation}

The duration of time between FCC exposure and health impact in humans can be very long, and suitable longitudinal studies in the human population are mostly lacking [125]. Therefore, linking FCC exposure to adverse human health outcomes is very difficult for many relevant substances.

Furthermore, in epidemiology, exposures to FCCs are often not routinely assessed [126] and only studied for very few individual FCCs. For some of the most controversial chemicals like bisphenol $\mathrm{A}$ and phthalates, 
evidence continues to accumulate while thousands of other FCCs that migrate into food lack hazard and/or exposure information [127-129]. Therefore, a systematic assessment of the available evidence is required [130] in order to identify and address pertinent knowledge gaps. This is of urgency also for economic reasons, as the additional disease costs related to exposures to endocrine disrupting chemicals are significant, with annually US\$ 340 billion in the US and US\$ 217 billion in the EU [131].

\section{Part 3. Options for improvement}

There is clear scientific evidence that chemicals migrate from food contact articles, and it is likely that the majority of the human population is affected by these exposures. Some of the migrating chemicals are known hazardous substances. Establishing causality between chronic human exposure to chemicals from food packaging (or other types of food contact articles) and adverse health outcomes in humans is difficult. As a consequence, there is a potentially large, but essentially unquantified, burden of risk currently placed on citizens who are unknowingly ingesting mixtures of unidentified and untested chemicals that originate from food contact articles with their daily food.

In addition, food packaging is of special interest in discussions around the circular economy, and many solutions are currently being proposed for reuse, recycling or replacing plastic food packaging with alternative materials. But those solutions mostly focus only on single aspects such as reducing $\mathrm{CO}_{2}$ emissions, energy use or plastic littering, and often omit considerations of chemical safety. This may lead to regrettable substitutions that cause problems later.

Therefore, we urge policy makers, regulators, food and food packaging manufacturers, civil society and scientists from within the FCM world, and outside, to address more attention to the issue of assessing the safety of food contact chemicals, as it appears to be an important opportunity for prevention of chronic diseases associated with hazardous chemical exposures. We identify seven areas of highest concern where we see an urgent need for discussion and improvement:

\section{Eliminating hazardous chemicals in food contact articles}

Known hazardous chemicals should not be used in the manufacture of food contact articles if their presence in the finished article, by means of modern chemical analysis, cannot be excluded to a reasonable extent. Some business operators have taken action on their food packaging in the US [132], but other food contact articles, such as processing equipment or filling lines, need to be considered as well, and requirements should become legally binding to encompass all food contact articles. Authorized lists of chemicals for food contact uses should be revised and known hazardous chemicals removed, such as substances of very high concern (SVHC), if their use is considered non-essential [133].

\section{Developing safer alternatives}

If the use of known hazardous chemicals is essential and currently no suitable substitutes are available, research into developing safer alternatives should be a priority. The development of safer alternatives should be based on current scientific principles, such as the Tiered Protocol for Endocrine Disruption (TiPED) [134], as the safety definitions and related criteria for establishing the risk of FCCs for human health currently in place in the EU, US and elsewhere are not aligned with the latest scientific understanding [1]. Importantly, hazard identification and characterization should be performed prior to large-scale FCC use.

\section{Modernizing risk assessment}

Together with industry and civil society, regulatory agencies should update what hazard and exposure data are necessary for making safety determinations, based on current scientific understanding [1]. Authorized substances for food contact that are currently in use should be reassessed accordingly; this will also require a transparent prioritization strategy that determines which chemicals are reassessed first. Any values-based or expert decisions affecting, for example, exposure estimates, should be made transparent, e.g. when dealing with data gaps or scientific uncertainty [135].

\section{Including endocrine disruption}

Chemical hazards related to endocrine disruption should be assessed for all chemicals migrating from food contact articles and for all substances that are intentionally used in their manufacture. It is important to consider the non-monotonic dose response phenomenon in chemical risk assessment [135].

\section{Addressing mixture toxicity}

The mixture toxicity of the overall migrate, i.e. all chemicals migrating from food contact articles, should be determined for a relevant set of hazards such as genotoxicity, mutagenicity, and endocrine disruption. This means that finished food contact articles should be tested in addition to single chemicals intentionally used in their manufacture. Regulators and other stakeholders should invest in research and development for fast or high-throughput approaches to screen the overall migrate. A general mixture toxicity uncertainty factor should be introduced until better approaches for dealing with mixtures have been developed. 


\section{Improving enforcement}

Importantly, new regulations must be enforceable, and sufficient resources for compliance control must be made available to authorities [136]. Enforcement of rules for known hazardous chemicals, such as carcinogens, is necessary. Food contact articles should not be a source of carcinogens migrating into food [128, 129, 137]. Enforcement of rules on mixture toxicity must also be practically feasible.

\section{Finding practical solutions}

A multi-stakeholder dialogue should be established to identify solutions that are sustainable and focus on the same goal, namely protecting humans and the environment while providing effective, efficient and affordable food packaging in a circular economy. Such solutions may be global in scope, but stakeholder needs will likely vary between countries and cultural regions, and such needs must be taken into account. Importantly, the interface between food packaging and waste management should be considered when new, practical solutions are developed [138].

In Table 2, we provide an overview of different topics that are relevant for the areas of concern.

\section{Conclusions}

We highlight that the human population is exposed via food to chemicals migrating from food contact articles such as food packaging. Many of these chemicals are not sufficiently assessed for their impacts on human health, while others are known hazardous substances. As a consequence, we see a need for revising how the safety of migrating chemicals is assessed, using current scientific understanding. At the same time, different stakeholders are pushing for solutions to reduce packaging waste and end plastic pollution, but oftentimes not taking chemical safety into consideration. Therefore, we encourage all stakeholders to focus more on this issue and employ science-based decision making in the interest of improving public health. Reducing exposure to hazardous food contact chemicals contributes to the prevention of associated diseases in humans. And including chemical safety considerations in the development of sustainable packaging will lead to solutions that are beneficial to both human and environmental health.

\section{Abbreviations}

FCC: Food contact chemical; NIAS: Non-intentionally added substance; REACH: Registration, Evaluation, Authorisation and Restriction of Chemicals; SVHC: Substance of Very High Concern; TiPED: Tiered protocol for endocrine disruption

\section{Authors' contributions}

The content of the manuscript was drafted by JM and MS and revised by MVM, JPM and RTZ. JM, MVM, JPM, MS and RTZ wrote the first draft. The first draft and the revised manuscript was discussed during several conference calls with all co-authors participating in some or all calls. All authors provided written feedback and edits on the manuscript and agreed with its content.

\section{Funding}

This work has been funded by the Food Packaging Forum Foundation (FPF) and the Plastics Solution Fund (PSF). PSF had no role in drafting the manuscript.

Availability of data and materials

Not applicable.

Ethics approval and consent to participate

Not applicable.

Consent for publication

Not applicable.

\section{Competing interests}

JM, BG and KG are employees of the Food Packaging Forum (FPF), a charitable foundation dedicated to science communication and research on chemicals in all types of food contact materials and articles. FPF's funding relies on unconditional donations and project-related grants, including from corporations in the glass packaging industry and foundations involved in the prevention of plastic pollution. JB, MVM and OVM have project-based contracts for working with FPF and receive remuneration for this role from FPF. TB, JPM and MS are members of the FPF foundation board, and they are not remunerated for this role. TB and MS are also board members of the International Panel on Chemical Pollution (IPCP), an NGO that works on the issue of chemical pollution in general. Both do not receive any personal benefits from this work, financial or otherwise. AMA, DG, JHeindel, MVM, OVM, AN, CN, AMS, LT, MW and RTZ are members of the FPF scientific advisory board and they are not remunerated for this role but have received travel reimbursement from FPF for attending its meetings. BCA is a project partner in a project coordinated by FPF and funded by MAVA Foundation and receives funding for this work via FPF. JC, BAD, JBF, JHoulihan, CDK, KP, RMS and LV are members of the scientific advisory group in a project coordinated by FPF and funded by the Plastics Solution Fund, but they have not received funding for this role. LNV has received funding from the US NIH, Cornell Douglas foundation and Paul G. Allen Foundation. She has been reimbursed for travel expenses by numerous organizations including SweTox, Israel Environment Fund, the Mexican Endocrine Society, Advancing Green Chemistry, ShiftCon, US EPA, Croplife America, BeautyCounter, and many universities to speak about endocrine disrupting chemicals. OVM is a European Parliament representative on the European Chemical Agency Management Board and has been appointed on the Joint Expert Group on Additives, Enzymes and other Regulated Products of the UK Food Standard Agency. MVM works with NGOs and the private sector on safety of FCCs. She has co-authored petitions requesting U.S. FDA to revoke uses of FCC and food additives. BD is a COfounder of the Watchfrog company but receives no financial compensation. All other authors declare no competing interests.

\section{Author details}

${ }^{1}$ Food Packaging Forum Foundation, Zurich, Switzerland. ${ }^{2}$ Department of Growth and Reproduction, International Center for Research and Research Training in Endocrine Disruption of Male Reproduction and Child Health (EDMaRC), Rigshospitalet, University of Copenhagen, Copenhagen, Denmark. ${ }^{3}$ Department of Biological and Environmental Sciences, University of Gothenburg, Gothenburg, Sweden. ${ }^{4}$ Institute of Biogeochemistry and Pollutant Dynamics, ETH Zurich, Zurich, Switzerland. ${ }^{5}$ Centre for Environmental Policy, Imperial College London, London, UK. ${ }^{6}$ Department of Epidemiology, Biostatistics and Occupational Health, Faculty of Medicine,

McGill University, Montreal, QC, Canada. Department Adaptation du Vivant, Unité mixte de recherche 7221, CNRS (French National Research Center) and Muséum National d'Histoire Naturelle, Paris, France. ${ }^{8}$ Institute of Environmental \& Marine Sciences, Silliman University, Dumaguete, Philippines. ${ }^{9}$ Institute of Environment, Health and Societies, Brunel University, Uxbridge, UK. ${ }^{10}$ Healthy Environment and Endocrine Disruptor Strategies, Commonweal, Bolinas, CA, USA. ${ }^{11}$ Healthy Babies Bright Futures,

Charlottesville, V.A., USA. ${ }^{12}$ Nicholas School of the Environment, Duke University, Durham, NC, USA. ${ }^{13}$ The Endocrine Disruption Exchange, Eckert, CO, USA. ${ }^{14}$ Center for Science in the Public Interest, Washington, DC, USA. 
${ }^{15}$ Independent Consultant, Frederick, MD, USA. ${ }^{16}$ Institute for the Environment, Health and Societies, Brunel University London, Uxbridge, UK. ${ }^{17}$ Environmental Health Sciences, Charlottesville, Virginia, USA. ${ }^{18}$ Department of Chemistry, Carnegie, Mellon University, Pittsburgh, PA, USA. ${ }^{19} \mathrm{IDiBE}$ and CIBERDEM, Universitas Miguel Hernandez, Elche, Spain. ${ }^{20}$ University of Zaragoza, I3A, Zaragoza, Spain. ${ }^{21}$ Green Science Policy Institute, Berkeley, CA, USA. ${ }^{22}$ Division of Endocrinology, Diabetes, and Metabolism, Department of Medicine, University of Illinois at Chicago, Chicago, IL, USA. ${ }^{23}$ Department of Immunology, Tufts University School of Medicine, Boston, MA, USA.

${ }^{24}$ Department of Pediatrics, NYU Grossman School of Medicine, New York, NY, USA. ${ }^{25}$ Department of Environmental Health Sciences, School of Public Health \& Health Sciences, University of Massachusetts Amherst, Amherst, MA, USA. ${ }^{26}$ Department of Biology, Norwegian University of Science and Technology (NTNU), Trondheim, Norway. ${ }^{27}$ Department of Animal and Food Sciences, University of Delaware, Newark, DE, USA. ${ }^{28}$ Department of Biology, University of Massachusetts Amherst, Amherst, MA, USA. ${ }^{29}$ RECETOX, Masaryk University, Brno, Czech Republic.

Received: 7 June 2019 Accepted: 4 February 2020

Published online: 03 March 2020

\section{References}

1. Muncke J, Backhaus T, Geueke B, Maffini MV, Martin OV, Myers JP, et al. Scientific challenges in the risk assessment of food contact materials. Environ Health Perspect. 2017;125(9):095001.

2. European Union. REGULATION (EC) No. 1935/2004 on materials and articles intended to come into contact with food and repealing Directives 80/590/ EEC and 89/109/EEC. EUROPEAN UNION. (EC) No. 1935/2004. 2004.

3. Grob K, Biedermann M, Scherbaum E, Roth M, Rieger K. Food contamination with organic materials in perspective: packaging materials as the largest and least controlled source? A view focusing on the European situation. Crit Rev Food Sci Nutr. 2006;46(7):529-35.

4. Calafat A, Ye X, Wong LY, Reidy JA, Needham LL. Exposure of the U.S. population to bisphenol a and 4-tertiary-octylphenol: 2003-2004. Environ Health Perspect. 2008;116(1):39-44.

5. Calafat A, Kuklenyik Z, Reidy JA, Caudill SP, Ekong J, Needham LL. Urinary concentrations of bisphenol a and 4-nonylphenol in a human reference population. Environ Health Perspect. 2005;113(4):391-5.

6. Koch HM, Muller J, Angerer J. Determination of secondary, oxidised diiso-nonylphthalate (DINP) metabolites in human urine representative for the exposure to commercial DINP plasticizers. J Chromatogr B. 2007; 847(2):114-25.

7. Koch HM, Preuss R, Drexler $\mathrm{H}$, Angerer J. Exposure of nursery school children and their parents and teachers to di-n-butylphthalate and butylbenzylphthalate. Int Arch Occup Environ Health. 2005;78(3):223-9.

8. Fromme H, Bolte G, Koch HM, Angerer J, Boehmer S, Drexler H, et al. Occurrence and daily variation of phthalate metabolites in the urine of an adult population. Int J Hyg Environ Health. 2007;210(1):21-33.

9. Fromme H, Midasch O, Twardella D, Angerer J, Boehmer S, Liebl B. Occurrence of perfluorinated substances in an adult German population in southern Bavaria. Int Arch Occup Environ Health. 2007;80(4):313-9.

10. Pouech C, Kiss A, Lafay F, Léonard D, Wiest L, Cren-Olivé C, et al. Human exposure assessment to a large set of polymer additives through the analysis of urine by solid phase extraction followed by ultra high performance liquid chromatography coupled to tandem mass spectrometry. J Chromatogr A. 2015;1423(Supplement C):111-23.

11. Wang $L$, Wu Y, Zhang W, Kannan K. Widespread occurrence and distribution of bisphenol a diglycidyl ether (BADGE) and its derivatives in human urine from the United States and China. Environ Sci Technol. 2012;46(23):12968-76.

12. Crump KS. Use of threshold and mode of action in risk assessment. Crit Rev Toxicol. 2011;41(8):637-50.

13. Crump KS, Hoel DG, Langley CH, Peto R. Fundamental carcinogenic processes and their implications for low dose risk assessment. Cancer Res. 1976;36(9 pt.1):2973-9.

14. Vandenberg LN, Colborn T, Hayes TB, Heindel JJ, Jacobs DR, Lee D-H, et al. Hormones and endocrine-disrupting chemicals: low-dose effects and nonmonotonic dose responses. Endocr Rev. 2012;33(3):378-455.

15. Zoeller RT, Brown TR, Doan LL, Gore AC, Skakkebaek NE, Soto AM, et al. Endocrine-disrupting chemicals and public health protection: a statement of principles from the Endocrine Society. Endocrinology. 2012;153(9):4097-110.

16. Diamanti-Kandarakis E, Bourguignon JP, Giudice LC, Hauser R, Prins GS, Soto AM, et al. Endocrine-disrupting chemicals: an Endocrine Society scientific statement. Endocr Rev. 2009;30(4):293-342.

17. Myers J, Zoeller R. Vom Saal F. A clash of old and new scientific concepts in toxicity, with important implications for public health. Environ Health Perspect. 2009;117(11):652-5.

18. Gore AC, Chappell VA, Fenton SE, Flaws JA, Nadal A, Prins GS, et al. EDC-2: the Endocrine Society's second scientific statement on endocrine-disrupting chemicals. Endocr Rev. 2015;36(6):E1-E150.

19. Gore AC, Chappell VA, Fenton SE, Flaws JA, Nadal A, Prins GS, et al. Executive summary to EDC-2: the Endocrine Society's second scientific statement on endocrine-disrupting chemicals. Endocr Rev. 2015;36(6):593-602.

20. Demeneix BA, Slama R. Endocrine Disruptors: From the scientific evidence to human health protection. European Parliament; 2019. Available: http:// www.europarl.europa.eu/thinktank/fr/document.html?reference=IPOL_STU(2 019)608866. Accessed 29 Nov 2019.

21. Tanner EM, Hallerbäck MU, Wikström S, Lindh C, Kiviranta H, Gennings $C_{\text {, }}$ et al. Early prenatal exposure to suspected endocrine disruptor mixtures is associated with lower IQ at age seven. Environ Int. 2020;134:105185.

22. Axelstad M, Hass U, Scholze M, Christiansen S, Kortenkamp A, Boberg J. EDC IMPACT: Reduced sperm counts in rats exposed to human relevant mixtures of endocrine disrupters. Endocr Connect. 2018;7(1):139-48.

23. Kortenkamp A, Faust $M$. Regulate to reduce chemical mixture risk. Science. 2018;361(6399):224-6.

24. Gaudriault P, Mazaud-Guittot S, Lavoué V, Coiffec I, Lesné L, DejucqRainsford N, et al. Endocrine disruption in human fetal testis explants by individual and combined exposures to selected pharmaceuticals, pesticides, and environmental pollutants. Environ Health Perspect. 2017; 125(8):087004.

25. Heindel JJ, Vandenberg LN. Developmental origins of health and disease: a paradigm for understanding disease cause and prevention. Curr Opin Pediatr. 2015;27(2):248-53.

26. COMMISSION REGULATION (EU) No 10/2011 of 14 January 2011 on plastic materials and articles intended to come into contact with food, (2011). Art. 13.2 and 14.2; Annex I.

27. Pieke EN, Smedsgaard J, Granby K. Exploring the chemistry of complex samples by tentative identification and semiquantification: a food contact material case. J Mass Spectrom. 2018;53(4):323-35.

28. EEA. Paving the way for a circular economy: insights on status and potentials. 2019. Available: https://www.eea.europa.eu/publications/circulareconomy-in-europe-insights. Accessed 29 Nov 2019.

29. Gilbert SG. Migration of minor constituents from food packaging materials. Food Sci. 1976;41(4):955-8

30. Koros WJ, Hopfenberg HB. Scientific aspects of migration of indirect additives from plastics to food. Food Technol-Chicago. 1979;33(4):56-60.

31. Till D, Schwope AD, Ehntholt DJ, Sidman KR, Whelan RH, Schwartz PS, et al. Indirect food additive migration from polymeric food-packaging materials. Crit Rev Toxicol. 1987;18(3):215-43.

32. Arvanitoyannis IS, Bosnea L. Migration of substances from food packaging materials to foods. Crit Rev Food Sci Nutr. 2004;44(2):63-76.

33. Melnick D, Luckmann FH. Sorbic acid as a fungistatic agent for foods. 4. Migration of sorbic acid from wrapper into cheese. Food Res. 1954; 19(1):28-32.

34. Shotyk W, Krachler M. Lead in bottled waters: contamination from glass and comparison with pristine groundwater. Environ Sci Technol. 2007:41(10):3508-13.

35. Andra SS, Makris KC, Shine JP, Lu C. Co-leaching of brominated compounds and antimony from bottled water. Environ Int. 2012;38(1):45-53.

36. Haldimann M, Alt A, Blanc A, Brunner K, Sager F, Dudler V. Migration of antimony from PET trays into food simulant and food: determination of Arrhenius parameters and comparison of predicted and measured migration data. Food Addit Contam A. 2013;30(3):587-98.

37. Hansen C, Tsirigotaki A, Bak SA, Pergantis SA, Sturup S, Gammelgaard B, et al. Elevated antimony concentrations in commercial juices. J Environ Monit. 2010;12(4):822-4.

38. Hansen HR, Pergantis SA. Detection of antimony species in citrus juices and drinking water stored in PET containers. J Anal At Spectrom. 2006:21(8):731-3.

39. Mihucz VG, Záray G. Occurrence of antimony and phthalate esters in polyethylene terephthalate bottled drinking water. Appl Spectrosc Rev. 2016;51(3):183-209. 
40. Shotyk W, Krachler M. Contamination of bottled waters with antimony leaching from polyethylene terephthalate (PET) increases upon storage. Environ Sci Technol. 2007;41(5):1560-3.

41. Shotyk W, Krachler M, Chen B. Contamination of Canadian and European bottled waters with antimony from PET containers. J Environ Monit. 2006:8(2):288-92.

42. Welle F, Franz R. Migration of antimony from PET bottles into beverages: determination of the activation energy of diffusion and migration modelling compared with literature data. Food Addit Contam A. 2011;28(1):115-26.

43. Westerhoff $P$, Prapaipong P, Shock E, Hillaireau A. Antimony leaching from polyethylene terephthalate (PET) plastic used for bottled drinking water. Water Res. 2008;42(3):551-6.

44. Bagnati R, Bianchi G, Marangon E, Zuccato E, Fanelli R, Davoli E. Direct analysis of isopropylthioxanthone (ITX) in milk by high-performance liquid chromatography/tandem mass spectrometry. Rapid Commun Mass Spectrom. 2007;21(13):1998-2002.

45. Morlock G, Schwack W. Determination of isopropylthioxanthone (ITX) in milk, yoghurt and fat by HPTLC-FLD, HPTLC-ESI/MS and HPTLC-DART/MS. Anal Bioanal Chem. 2006;385(3):586-95.

46. Rothenbacher T, Baumann M, Fugel D. 2-Isopropylthioxanthone (2-ITX) in food and food packaging materials on the German market. Food Addit Contam. 2007;24(4):438-44.

47. Sagratini G, Manes J, Giardina D, Pico Y. Determination of isopropyl thioxanthone (ITX) in fruit juices by pressurized liquid extraction and liquid chromatography-mass spectrometry. J Agric Food Chem. 2006;54(20):7947-52.

48. Castle L, Damant AP, Honeybone CA, Johns SM, Jickells SM, Sharman M, et al. Migration studies from paper and board food packaging materials. Part 2. Survey for residues of dialkylamino benzophenone UV-cure ink photoinitiators. Food Addit Contam. 1997;14(1):45-52.

49. Bradley EL, Driffield M, Harmer N, Oldring PKT, Castle L. Identification of potential migrants in epoxy phenolic can coatings. Int J Polym Anal Charact. 2008;13(3):200-23.

50. Castle L, Mayo A, Crews C, Gilbert J. Migration of poly (ethylene terephthalate) (PET) oligomers from PET plastics into foods during microwave and conventional cooking and into bottled beverages. J Food Prot. 1989;52(5):337-42.

51. Jickells SM, Gramshaw JW, Castle L, Gilbert J. The effect of microwave energy on specific migration from food contact plastics. Food Addit Contam. 1992;9(1):19-27.

52. Begley TH, Hsu W, Noonan G, Diachenko G. Migration of fluorochemical paper additives from food-contact paper into foods and food simulants. Food Addit Contam A. 2008;25(3):384-90.

53. Biles JE, McNeal TP, Begley TH. Determination of bisphenol a migrating from epoxy can coatings to infant formula liquid concentrates. J Agric Food Chem. 1997;45(12):4697-700.

54. Grob K, Spinner C, Brunner M, Etter R. The migration from the internal coatings of food cans; summary of the findings and call for more effective regulation of polymers in contact with foods: a review. Food Addit Contam. 1999:16(12):579-90.

55. Biedermann S, Zurfluh M, Grob K, Vedani A, Brüschweiler BJ. Migration of cyclo-diBA from coatings into canned food: method of analysis, concentration determined in a survey and in silico hazard profiling. Food Chem Toxicol. 2013;58(0):107-15.

56. Schaefer A, Maß S, Simat TJ, Steinhart H. Migration from can coatings: part 1. A size-exclusion chromatographic method for the simultaneous determination of overall migration and migrating substances below 1000 Da. Food Addit Contam. 2004;21(3):287-301.

57. Lickly TD, Bell CD, Lehr KM. The migration of irganox 1010 antioxidant from high-density polyethylene and polypropylene into a series of potential fattyfood simulants. Food Addit Contam. 1990;7(6):805-14.

58. Rybak KE, Sarzynski W, Dawidowicz AL. Migration of antioxidant additives from polypropylene investigated by means of reversed phase high-performance liquid-chromatography. Chem Anal-Warsaw. 1992;37(2):149-59.

59. Berg BE, Hegna DR, Orlien N, Greibrokk T. Determination of low-levels of polymer additives migrating from polypropylene to food simulated liquids by capillary SFC and solvent venting injection. Chromatographia. 1993;37(56):271-6.

60. Perring L, Basic-Dvorzak M. Determination of total tin in canned food using inductively coupled plasma atomic emission spectroscopy. Anal Bioanal Chem. 2002;374:235-43.
61. Demont M, Boutakhrit K, Fekete V, Bolle F, Van Loco J. Migration of 18 trace elements from ceramic food contact material: influence of pigment, $\mathrm{pH}$, nature of acid and temperature. Food Chem Toxicol. 2012:50(3-4):734-43.

62. Suciu NA, Tiberto F, Vasileiadis S, Trevisan M. Recycled paper-paperboard for food contact materials: contaminants suspected and migration into foods and food simulant. Food Chem. 2013;141(4):4146-51.

63. Yuan G, Peng H, Huang C, Hu J. Ubiquitous occurrence of fluorotelomer alcohols in eco-friendly paper-made food-contact materials and their implication for human exposure. Environ Sci Technol. 2016;50(2):942-50.

64. Asensio E, Peiro T, Nerín C. Determination the set-off migration of ink in cardboard-cups used in coffee vending machines. Food Chem Toxicol. 2019:130:61-7.

65. Ubeda S, Aznar M, Alfaro P, Nerín C. Migration of oligomers from a food contact biopolymer based on polylactic acid (PLA) and polyester. Anal Bioanal Chem. 2019.

66. Aznar M, Ubeda S, Dreolin N, Nerín C. Determination of non-volatile components of a biodegradable food packaging material based on polyester and polylactic acid (PLA) and its migration to food simulants. J Chromatogr A. 2019;1583:1-8.

67. Groh K, Geueke B, Muncke J. FCCdb: Food Contact Chemicals database. https://doi.org/10.5281/zenodo.3240108. Zenodo; 2020. Accessed 25 Feb 2020.

68. Simoneau C, Raffael B, Garbin S, Hoekstra E, Mieth A, Alberto Lopes JF, et al. Non-harmonised food contact materials in the EU: regulatory and market situation: BASELINE STUDY: final report. 2016. Available: https://publications. jrc.ec.europa.eu/repository/handle/JRC104198. Accessed 29 Nov 2019.

69. Neltner TG, Kulkarni NR, Alger HM, Maffini MV, Bongard ED, Fortin ND, et al. Navigating the U.S. food additive regulatory program. Compr Rev Food Sci F. 2011;10(6):342-68.

70. Neltner TG, Alger HM, O'Reilly JT, Krimsky S, Bero LA, Maffini MV. Conflicts of interest in approvals of additives to food determined to be generally recognized as safe: out of balance. JAMA Intern Med. 2013;173(22):2032-6.

71. Biryol D, Nicolas Cl, Wambaugh J, Phillips K, Isaacs K. High-throughput dietary exposure predictions for chemical migrants from food contact substances for use in chemical prioritization. Environ Int. 2017;108:185-94.

72. Groh KJ, Backhaus T, Carney-Almroth B, Geueke B, Inostroza PA, Lennquist A, et al. Overview of known plastic packaging-associated chemicals and their hazards. Sci Total Environ. 2019;651:3253-68.

73. Muncke J. Exposure to endocrine disrupting compounds via the food chain: is packaging a relevant source? Sci Total Environ. 2009;407(16):4549-59.

74. Rosenmai AK, Bengtström L, Taxvig C, Trier X, Petersen JH, Svingen T, et al. An effect-directed strategy for characterizing emerging chemicals in food contact materials made from paper and board. Food Chem Toxicol. 2017; 106(Part A):250-9.

75. Mertl J, Kirchnawy C, Osorio V, Grininger A, Richter A, Bergmair J, et al. Characterization of estrogen and androgen activity of food contact materials by different in vitro bioassays (YES, YAS, ERalpha and AR CALUX) and chromatographic analysis (GC-MS, HPLC-MS). PLoS One. 2014;9(7):e100952.

76. Kirchnawy C, Mertl J, Osorio V, Hausensteiner H, Washüttl M, Bergmair J, et al. Detection and identification of oestrogen-active substances in plastic food packaging migrates. Packag Technol Sci. 2014;27(6):467-78.

77. Nerin C, Canellas E, Vera P, Garcia-Calvo E, Luque-Garcia JL, Cámara C, et al. A common surfactant used in food packaging found to be toxic for reproduction in mammals. Food Chem Toxicol. 2018;113:115-24.

78. Oldring PKT, O'Mahony C, Dixon J, Vints M, Mehegan J, Dequatre C, et al. Development of a new modelling tool (FACET) to assess exposure to chemical migrants from food packaging. Food Addit Contam A. 2014;31(3):444-65

79. Alger HM, Maffini MV, Kulkarni NR, Bongard ED, Neltner T. Perspectives on how FDA assesses exposure to food additives when evaluating their safety: workshop proceedings. Compr Rev Food Sci F. 2013;12(1):90-119.

80. Geueke B, Wagner CC, Muncke J. Food contact substances and chemicals of concern: a comparison of inventories. Food Addit Contam A. 2014;31 (8):1438-50.

81. Geueke B, Muncke J. Substances of very high concern in food contact materials: migration and regulatory background. Packag Technol Sci. 2018;31(12):757-69.

82. Scheringer $M$, Trier $X$, Cousins IT, de Voogt $P$, Fletcher $T$, Wang $Z$, et al. Helsingør statement on poly- and perfluorinated alkyl substances (PFASs). Chemosphere. 2014;114:337-9.

83. Trier X, Granby K, Christensen J. Polyfluorinated surfactants (PFS) in paper and board coatings for food packaging. Environ Sci Pollut R. 2011;18(7):1108-20. 
84. Schaider LA, Balan SA, Blum A, Andrews DQ, Strynar MJ, Dickinson ME, et al. Fluorinated compounds in U.S. fast food packaging. Environ Sci Technol Lett. 2017;4(3):105-11.

85. Hill D. Comments on Natural Resources Defense Council et al.: filing of Food Additive Petition on Perchlorates; Docket No. FDA-2015-F-0537. 2015. Available: http://blogs.edf.org/health/files/2018/12/Perchlorate-BASFMigration-Test-and-Cover-Letter-11-4-15.pdf. Accessed 29 Nov 2019.

86. Koster S, Rennen M, Leeman W, Houben G, Muilwijk B, van Acker F, et al. A novel safety assessment strategy for non-intentionally added substances (NIAS) in carton food contact materials. Food Addit Contam A. 2013;31(3):422-43.

87. Nerin C, Alfaro P, Aznar M, Domeño C. The challenge of identifying nonintentionally added substances from food packaging materials: A review. Anal Chim Acta. 2013;775(2 May 2013):14-24.

88. Hoppe $M$, de Voogt P, Franz R. Identification and quantification of oligomers as potential migrants in plastics food contact materials with a focus in polycondensates - a review. Trends Food Sci Technol. 2016;50:118-30.

89. Bradley E, Coulier L. An investigation into the reaction and breakdown products from starting substances used to produce food contact plastics. Report. London: Central Science Laboratory; 2007. August 2007. Report No.: FD 07/01 Contract No.: FD07/01.

90. Qian S, Ji H, Wu X, Li N, Yang Y, Bu J, et al. Detection and quantification analysis of chemical migrants in plastic food contact products. PLoS One. 2018;13(12):e0208467.

91. Wagner M, Schlüsener MP, Ternes TA, Oehlmann J. Identification of putative steroid receptor antagonists in bottled water: combining bioassays and high-resolution mass spectrometry. PLoS One. 2013;8(8):e72472.

92. Bengtström L, Rosenmai AK, Trier X, Jensen LK, Granby K, Vinggaard AM, et al. Non-targeted screening for contaminants in paper and board food contact materials using effect directed analysis and accurate mass spectrometry. Food Addit Contam A. 2016;33(6):1080-93.

93. Pieke EN, Granby K, Teste B, Smedsgaard J, Riviere G. Prioritization before risk assessment: the viability of uncertain data on food contact materials. Regul Toxicol Pharmacol. 2018;97:134-43.

94. Pieke EN, Granby K, Trier X, Smedsgaard J. A framework to estimate concentrations of potentially unknown substances by semi-quantification in liquid chromatography electrospray ionization mass spectrometry. Anal Chim Acta. 2017:975:30-41.

95. Zimmermann L, Dierkes G, Ternes TA, Völker C, Wagner M. Benchmarking the in vitro toxicity and chemical composition of plastic consumer products. Environ Sci Technol. 2019;53(19):11467-77.

96. Biedermann M, Grob K. Is comprehensive analysis of potentially relevant migrants from recycled paperboard into foods feasible? J Chromatogr A. 2013;1272(0):106-15

97. US EPA. EPA Releases First Major Update to Chemicals List in 40 Years US EPA; 2019. Available: https://www.epa.gov/newsreleases/epa-releases-first-majorupdate-chemicals-list-40-years. Accessed 29 Nov 2019.

98. ECHA. Registered substances. ECHA; 2019. Available: https://echa.europa.eu/ information-on-chemicals/registered-substances. Accessed 29 Nov 2019.

99. Koch HM, Lorber M, Christensen KLY, Pälmke C, Koslitz S, Brüning T. Identifying sources of phthalate exposure with human biomonitoring: results of a $48 \mathrm{~h}$ fasting study with urine collection and personal activity patterns. Int J Hyg Environ Health. 2013;216(6):672-81.

100. Vandenberg LN, Chauhoud I, Heindel JJ, Padmanabhan V, Paumgartten FJ, Schoenfelder G. Urinary, circulating and tissue biomonitoring studies indicate widespread exposure to bisphenol a. Environ Health Perspect. 2010;118(8):1055-70.

101. Geens T, Aerts D, Berthot C, Bourguignon J-P, Goeyens L, Lecomte P, et al. A review of dietary and non-dietary exposure to bisphenol-a. Food Chem Toxicol. 2012;50(10):3725-40.

102. Fromme H, Tittlemier SA, Völkel W, Wilhelm M, Twardella D. Perfluorinated compounds - exposure assessment for the general population in western countries. Int J Hyg Environ Health. 2009:212(3):239-70.

103. Becker K, Güen T, Seiwert M, Conrad A, Pick-Fuß H, Müller J, et al. GerES IV: phthalate metabolites and bisphenol a in urine of German children. Int J Hyg Environ Health. 2009;212(6):685-92.

104. Calafat AM, Ye X, Wong L-Y, Reidy JA, Needham LL. Urinary concentrations of triclosan in the U.S. population: 2003-2004. Environ Health Perspect. 2008;116(3):303-7.

105. Varshavsky JR, Morello-Frosch R, Woodruff TJ, Zota AR. Dietary sources of cumulative phthalates exposure among the U.S. general population in NHANES 2005-2014. Environ Int. 2018;115:417-29.
106. Park YH, Lee K, Soltow QA, Strobel FH, Brigham KL, Parker RE, et al. Highperformance metabolic profiling of plasma from seven mammalian species for simultaneous environmental chemical surveillance and bioeffect monitoring. Toxicology. 2012;295(1):47-55.

107. Wang A, Gerona RR, Schwartz JM, Lin T, Sirota M, Morello-Frosch R, et al. A Suspect Screening Method for Characterizing Multiple Chemical Exposures among a Demographically Diverse Population of Pregnant Women in San Francisco. Environ Health Perspect. 2018;126(7):077009.

108. Wang A, Padula A, Sirota M, Woodruff TJ. Environmental influences on reproductive health: the importance of chemical exposures. Fertil Steril. 2016;106(4):905-29.

109. Lopez-Espinosa MJ, Silva E, Granada A, Molina-Molina JM, Fernandez MF, Aguilar-Garduno C, et al. Assessment of the total effective xenoestrogen burden in extracts of human placentas. Biomarkers. 2009;14(5):271-7.

110. Jiménez-Díaz I, Vela-Soria F, Rodríguez-Gómez R, Zafra-Gómez A, Ballesteros $\mathrm{O}$, Navalón A. Analytical methods for the assessment of endocrine disrupting chemical exposure during human fetal and lactation stages: a review. Anal Chim Acta. 2015;892:27-48.

111. Woodruff TJ, Zota AR, Schwartz JM. Environmental Chemicals in Pregnant Women in the United States: NHANES 2003-2004. Environ Health Perspect. 2011;119(6):878-85.

112. McCombie G. Enforcement's Perspective. In: European Commission, Directorate General Health and Food Safety; 2018. Available: https:/ec.europa.eu/food/ sites/food/files/safety/docs/cs_fcm_eval-workshop_20180924_pres07.pdf. Accessed 29 Nov 2019

113. Sanchis Y, Yusà V, Coscollà C. Analytical strategies for organic food packaging contaminants. J Chromatogr A. 2017;1490:22-46.

114. Martínez-Bueno MJ, Gómez Ramos MJ, Bauer A, Fernández-Alba AR. An overview of non-targeted screening strategies based on high resolution accurate mass spectrometry for the identification of migrants coming from plastic food packaging materials. TrAC-Trend Anal Chem. 2019;110:191-203.

115. Chen M-L, Chen J-S, Tang C-L, Mao IF. The internal exposure of Taiwanese to phthalate-an evidence of intensive use of plastic materials. Environ Int. 2008;34(1):79-85.

116. Japanese Ministry of Health. Overview of amendments to the Food Sanitation Act: Japanese Minstry of Health; 2019. Available: https://www.mhlw.go.jp/ content/11130500/000537821.pdf. Page 20. Accessed 29 Nov 2019.

117. FDA. Threshold of Regulations Exemptions. In: List of issued exemptions based on the Thresold of Regulation, since 1996; 2012. Available: https:/www.fda.gov/ food/packaging-food-contact-substances-fcs/threshold-regulation-exemptionssubstances-used-food-contact-articles. Accessed 29 Nov 2019.

118. Beausoleil C, Beronius A, Bodin L, Bokkers BGH, Boon PE, Burger M, et al. Review of non-monotonic dose-responses of substances for human risk assessment. EFSA Supporting Publications. 2016;13(5):1027E.

119. Hass U, Christiansen S, Andersson A-M, Holbech H, Bjerregaard P. Report on interpretation of knowledge on endocrine disrupting substances (EDs) what is the risk? 2019. Available: http://www.cend.dk/files/ED_Risk_reportfinal-2019.pdf. Accessed 29 Nov 2019

120. Evans RM, Martin OV, Faust M, Kortenkamp A. Should the scope of human mixture risk assessment span legislative/regulatory silos for chemicals? Sci Total Environ. 2016;543(Part A):757-64.

121. Veyrand J, Marin-Kuan M, Bezencon C, Frank N, Guérin $V$, Koster S, et al. Integrating bioassays and analytical chemistry as an improved approach to support safety assessment of food contact materials. Food Addit Contam A. 2017;34(10):1807-16

122. Groh KJ, Muncke J. In vitro toxicity testing of food contact materials: stateof-the-art and future challenges. Compr Rev Food Sci F. 2017;16(5):1123-50.

123. Severin I, Souton E, Dahbi L, Chagnon MC. Use of bioassays to assess hazard of food contact material extracts: state of the art. Food Chem Toxicol. 2017;105:429-47.

124. Severin I, Dahbi L, Lhuguenot JC, Andersson MA, Hoornstra D, SalkinojaSalonen M, et al. Safety assessment of food-contact paper and board using a battery of short-term toxicity tests: European union BIOSAFEPAPER project. Food Addit Contam. 2005;22(10):1032-41.

125. Lee D-H, Jacobs DR. Firm human evidence on harms of endocrinedisrupting chemicals was unlikely to be obtainable for methodological reasons. J Clin Epidemiol. 2019:107:107-15.

126. Muncke J, Myers JP, Scheringer M, Porta M. Food packaging and migration of food contact materials: will epidemiologists rise to the neotoxic challenge? J Epidemiol Commun H. 2014;68(7):592. 
127. Lang IA, Galloway TS, Scarlett A, Henley WE, Depledge M, Wallace RB, et al. Association of urinary bisphenol a concentration with medical disorders and laboratory abnormalities in adults. JAMA. 2008;300(11):1303-10.

128. Van Bossuyt M, Van Hoeck E, Vanhaecke T, Rogiers V, Mertens B. Prioritizing substances of genotoxic concern for in-depth safety evaluation using nonanimal approaches: the example of food contact materials. Altex-Altern Anim Ex. 2019;36(2):215-30.

129. Mertens B, Van Bossuyt M, Fraselle S, Blaude MN, Vanhaecke T, Rogiers V, et al. Coatings in food contact materials: potential source of genotoxic contaminants? Food Chem Toxicol. 2017;106:496-505.

130. Martin OV, Geueke B, Groh KJ, Chevrier J, Fini J-B, Houlihan J, et al. Protocol for a systematic map of the evidence of migrating and extractable chemicals from food contact articles. ZENODO. 2018; Available: https:// zenodo.org/record/2525277\#.XeF4Y-hKhjU. Accessed 29 Nov 2019.

131. Attina TM, Hauser R, Sathyanarayana S, Hunt PA, Bourguignon J-P, Myers JP, et al. Exposure to endocrine-disrupting chemicals in the USA: a populationbased disease burden and cost analysis. Lancet Diabetes Endocrinol. 2016;4(12):996-1003.

132. Groh K. Best practice for chemicals in food packaging. Food Packaging Forum; 2018. Available: https://www.foodpackagingforum.org/news/bestpractice-for-chemicals-in-food-packaging.

133. Cousins IT, Goldenman G, Herzke D, Lohmann R, Miller M, Ng CA, et al. The concept of essential use for determining when uses of PFASs can be phased out. Environ Sci-Proc Imp. 2019;21(11):1803-15.

134. Schug TT, Heindel JJ, Camacho L, Delclos KB, Howard P, Johnson AF, et al. A new approach to synergize academic and guideline-compliant research: the CLARITY-BPA research program. Reprod Toxicol. 2013;40(0):35-40.

135. Vandenberg LN, Hunt PA, Gore AC. Endocrine disruptors and the future of toxicology testing - lessons from CLARITY-BPA. Nat Rev Endocrinol. 2019;15(6):366-74.

136. Daniel J, Hoetzer K, McCombie G, Grob K. Conclusions from a Swiss official control of the safety assessment for food contact polyolefins through the compliance documentation of the producers. Food Addit Contam A. 2019;36(1):186-93.

137. Mertens B, Simon C, Van Bossuyt M, Onghena M, Vandermarken T, Van Langenhove $K$, et al. Investigation of the genotoxicity of substances migrating from polycarbonate replacement baby bottles to identify chemicals of high concern. Food Chem Toxicol. 2016;89:126-37.

138. Geueke B, Groh K, Muncke J. Food packaging in the circular economy: overview of chemical safety aspects for commonly used materials. J Clean Prod. 2018;193:491-505.

139. Grob K. Work plans to get out of the deadlock for the safety assurance of migration from food contact materials? A proposal Food Control. 2014:46(0):312-8.

140. Bosma M. A repository to support risk assessments of non-listed substances (NLS) and non-intentionally added substances (NIAS). In: Food Packaging Forum workshop 2019. Available: https://www.foodpackagingforum.org/ events/workshop2019 and https://youtu.be/2h-D4UwhmVE. Accessed 29 Nov 2019.

141. Schilter B, Burnett K, Eskes C, Geurts L, Jacquet M, Kirchnawy C, et al. Value and limitation of in vitro bioassays to support the application of the threshold of toxicological concern to prioritise unidentified chemicals in food contact materials. Food Addit Contam A. 2019;36(12):1903-36.

142. EFSA CEF Panel. Recent developments in the risk assessment of chemicals in food and their potential impact on the safety assessment of substances used in food contact materials. EFSA J. 2016;14(1):4357.

143. EURION-CLUSTER. European cluster to improve identification of endocrine disruptors 2019. Available: http://eurion-cluster.eu/. Accessed 29 Nov 2019.

144. Ernstoff A, Niero M, Muncke J, Trier X, Rosenbaum RK, Hauschild M, et al. Challenges of including human exposure to chemicals in food packaging as a new exposure pathway in life cycle impact assessment. Int I Life Cycle Assess. 2019;24(3):543-52.

\section{Publisher's Note}

Springer Nature remains neutral with regard to jurisdictional claims in published maps and institutional affiliations.

\section{Ready to submit your research? Choose BMC and benefit from:}

- fast, convenient online submission

- thorough peer review by experienced researchers in your field

- rapid publication on acceptance

- support for research data, including large and complex data types

- gold Open Access which fosters wider collaboration and increased citations

- maximum visibility for your research: over $100 \mathrm{M}$ website views per year

At BMC, research is always in progress.

Learn more biomedcentral.com/submissions 